\title{
The effect of sexual education program on spinal cord injured couples on disability acceptance, self-esteem, and marital relationship enhancement.
}

\author{
Mi-Jin Kim¹, Sun-Houng Kim², Young-Soon Choi ${ }^{3 *}$ \\ ${ }^{1}$ Department of Nursing, Shinhan University, 95, Hoam-ro, Uijeongbu-si, Gyeonggi-do, Republic of Korea \\ ${ }^{2}$ Department of Nursing, National Rehabilitation Center, 520, Suyu5-dong, Gangbuk-gu, Seoul, Republic of Korea \\ ${ }^{3}$ Department of Nursing, College of Health Science, Kangwon National University, Hwangjo-gil, Samcheok-si, \\ Gangwon-do, Republic of Korea
}

\begin{abstract}
This study is a single-group pre-post experimental design to investigate the effect of the sexual education treatment program of the spinal cord disabled on the acceptance of disability, self-esteem and marital relationship enhancement. Disability acceptance of the spinal cord injury couple, spinal cord injury group and spinal cord injury spouse group showed statistically significant changes in pre-immediately post and pre-post. The self-esteem of the spinal cord injury couple, the spinal cord injury group and the spinal cord injury spouse group was statistically significant in the pre-immediately post but not statistically in the pre-post. This study by verifying the effectiveness of sex education programs of the spinal cord disabilities to provide basic data for the program to accommodate disabilities and promote self-esteem of the spinal cord and the disabled couple, in addition, we aim to contribute to the establishment of healthy family relationships and the improvement of quality of life by promoting spousal couple's marital relationship.
\end{abstract}

Keywords: Sexual education program, Spinal cord injured couples, Disability acceptance, Self-esteem, Marital relationship.

Accepted on November 23, 2018

\section{Introduction}

According to a 2011 survey on 95 percent or more of people with spinal cord injury are people with the acquired disability that is impossible to treat with modern medicine. Once one has spinal cord injury, the person is likely to remains as a person with a disability [1], and it creates a huge negative impact to the patient's everyday life as well as their social lives [2].

This type of injury could give a patient severe discomfort to the point where he or she becomes handicapped or completely disabled. The biggest problems that people with spinal cord injury face are not only permanent functional disability such as quadriplegia or paraplegia but also the unpredictable future that is ascribed to various complications and trauma that may last or get aggravated during their lifetime, and they may encounter diverse psychosocial problems against their expectations as they realize they cannot recover to their previous physical function [3].

To facilitate the psychosocial adjustment of people with spinal cord injury, every possible help from their families seems to be necessary above all. Their families are one of the rehabilitation personnel from the beginning of the rehabilitation process. They are the ones that affect their mental attitude to the disease and its progress, and they serve as facilitators who help the patient overcome and adapt to the changes [4].

Married couples who have physical disabilities are confronted with a lot of psychosocial problems related to married life on account of the disabilities, and the problems are quite severe. As these couples are less aware of family reconstitution factor and purification factor than people without disabilities, their conflicts are so serious that they suppress their feelings. Accordingly, the development of group counseling programs that are different from programs geared toward people without disabilities is urgently required to improve their family reconstitution factor and purification factor [5].

In fact, the reality in our country is that there are few programs in which husbands and wives who both have spinal cord injury can participate together. Furthermore, people, in general, pay little attention to their psychosocial problems. Under the circumstances, it's necessary to develop marital sex education programs for their sake and to test what effects these programs have on their psychological problems, especially disability acceptance and self-esteem, with which both of them are troubled after being physically challenged. 
The purpose of this study was to examine the effects of a sexual education program on married couples with spinal cord injury in an attempt to provide some information on programs geared toward improving their disability acceptance and boosting their self-esteem, and it's further meant to make a contribution to the establishment of healthy family relations and the improvement of their quality of life by promoting their marital relationship.

\section{Research Method}

\section{Research design}

This study is a single group pre-post experiment design to investigate the effect of the sexual education program of spinal cord injury couple on the acceptance of disability, self-esteem, and marital relationship enhancement. Survey questionnaires for research were conducted 3 times (before program operation, immediately after operation, 2 months after operation). The preliminary questionnaire survey was conducted by mailing the questionnaire to the finalists of the program. Immediately after the program was run, the questionnaire survey was conducted on-site at the end of the program. The questionnaire after the program operation was conducted by visiting the survey two months after the end of the program.

\section{Research subjects}

The recruitment of spinal cord injured couples who are participating in the program was announced through press releases to newspapers and the press and internet homepage (Ministry of Health and Welfare, National Rehabilitation Center, Spinal Cord Association). Through the telephone and the internet, I received a request for the subject couple from August $15^{\text {th }}$ to $29^{\text {th }}, 2009$, for two weeks through the recommendation of the individual or spinal cord association and the national rehabilitation center social work team. The recruited subjects fully understood the purpose and procedure of the study and expressed their willingness to participate in the experiment and agreed in writing to participate in the study. Selection criteria are a legitimate couple is one of the spinal cord and the disabled person's disability and health status should attend this program was possible as a least 3 months after spinal cord injury, a total of 7 pairs were randomly extracted.

\section{Experimental method}

1) Study period: This study is an educational program with the theme "Creating a happy couple in spinal cord injury 'Training Center in Hoengseong, Gangwon Province for two nights and three days to verify the effectiveness of sex education programs from September $17^{\text {th }}$ to September $19^{\text {th }}$, 2009.

2) Sexual education program: In this study, the spinal cord injured couple sexual education program was $20 \mathrm{~h}$ in total and consisted of 5 parts. The details are divided into emotion $(4 \mathrm{~h})$, spouse understanding $(3 \mathrm{~h})$, future design $(3 \mathrm{~h})$, forest activities $(3 \mathrm{~h})$, marriage and sex $(4 \mathrm{~h})$ and others $(3 \mathrm{~h})$.

Sexual rehabilitation nurse took charge of the entire process of sexual education program, among the details, a division of feelings, understanding of spouse, and future design were handled by a couple counseling specialist, future design and other times were taken by the sexual rehabilitation nurse. The program was divided into group counseling for division of feelings and spouse understanding, group counseling and experience for future design, experience for forest activities, marriage and sex for lecture and discussion.

\section{Research tools}

1) Disability acceptance: Disability acceptance scale used disability acceptance part of disability identity scale developed by Lee [6]. The reliability Cronbach's $\alpha$ value of the disability identity tool was 0.87 , and the reliability Cronbach's $\alpha$ value of the disability acceptance tool was 0.65 . A total of 4 items were composed of 4 points. The higher the score, the better the acceptance of disability. This research tool was converted into a 5-point scale by the researcher and the reliability of the researcher's tool was Cronbach's $\alpha=0.92$.

2) Self-esteem: A measure of self-esteem was composed of Rosenberg Self- Esteem Scale with 4-point scale, a total of 10 questions [7], the higher the score, the higher the self-esteem. This tool consists of five positive and five negative questions, this study used the modified version of the tool by Jeon. The reliability of Cronbach's $\alpha=0.92$ in the development of the tool in 1965, Jeon tool reliability is Cronbach's $\alpha=0.62$, the reliability of the tools of this study Cronbach's $\alpha=0.72$.

3) Marital satisfaction: The Kansas Marriage Satisfaction Scale was developed by Walter and his colleagues as three items developed to evaluate the marital satisfaction of married couples. Kansas Marital Satisfaction Scale to investigate the couple's marital satisfaction is measured 7-point Likert type with respect to the spouse, marriage, marital relations, with the highest scores in addition to individual items it means contentment in marriage. The reliability of the Kansas marital satisfaction scale was Cronbach $\alpha=0.93$, and the reliability of this study was Cronbach's $\alpha=0.99$.

4) Sexual life satisfaction: As a general subject of anatomical and physiological aspects of sexual life, we used the tools modified by Jeong in the Derogatis Sex Function Inventory (DSFI) [8]. Of the total 11 items, 9 items were used except for 2 items with low answers in the pre-test. The reliability of the Jeong research was Cronbach $\alpha=0.79$, the reliability of the instrument in this study is Cronbach's $\alpha=0.75$.

\section{Data analysis method}

The collected data were analysed using the SPSS 21.0 program according to the purpose of the study. The demographic characteristics of the subjects were determined as number, percentage, mean and standard deviation. The pre-immediately 
The effect of sexual education program on spinal cord injured couples on disability acceptance, self-esteem, and marital relationship enhancement

post and pre-post change tests were analysed by the Wilcoxon sign rank test, which is a non-parametric statistic.

\section{Ethical considerations}

After explaining the purpose and method of the study and asking for permission, the study was conducted. The subjects' consent was based on existing research and explained that it consisted of research purpose, research procedure, research method, and voluntary participation. The subject can withdraw it at any time, without any disadvantages, and the collected data is not used for purposes other than all research.

\section{Results}

\section{Verification of differences in acceptance of disability}

As the acceptance of disability of the spinal cord injured couple was $2.34 \pm 0.96$ pre the program, $3.89 \pm 0.65$ immediately-post the program and $3.71 \pm 0.78$ post the program. Both pre-immediately post $(Z=0-3.31 \mathrm{p}<0.001)$, prepost $(Z=0-3.19 \mathrm{p}<0.001)$ it was statistically significant.

The spinal cord injury group and the spousal group were divided into two groups, in the spinal cord injury group, the disability acceptance average was changed to pre $2.46 \pm 51$ and immediately post $4.07 \pm 0.51$ it was statistically significant $(\mathrm{Z}=-2.217, \mathrm{p}<0.05)$, pre $2.46 \pm 51$ and post $3.50 \pm 0.58$ it was statistically significant results were obtained $(Z=-2.217$, $\mathrm{p}<0.05)$.

The spouse group examined the disability acceptance of the spouse, the average pre disability acceptance score was $2.21 \pm$ 0.81 , which was lower than the spinal injury group. The disability acceptance of the program was changed from pre $2.21 \pm 0.81$ to immediately post $3.71 \pm 0.76$, showed a statistically significant $\quad(Z=0-2.38, \quad \mathrm{p}<0.05), \quad$ pre-post comparison of the results showed a statistically significant change in pre $2.21 \pm 0.81$, post $3.93 \pm 0.93(\mathrm{Z}=-2.39, \mathrm{p}<0.05)$ (Table 1).

\section{Verification of differences in self-esteem}

The self-esteem of the spinal cord injured couple was $2.81 \pm$ 0.53 pre the program, $3.45 \pm 0.49$ immediately post the program, and $2.81 \pm 0.40$ post the program. Pre and immediately post $(Z=-3.19, p<0.001)$, it was statistically significant, pre and post it was statistically not significant.

The spinal cord injury group and the spousal group were divided into two groups, in the spinal cord injury group, the self-esteem average was changed to pre $2.81 \pm 0.50$ and immediately post $3.43 \pm 0.41$ it was statistically significant $(\mathrm{Z}=-2.21, \mathrm{p}<0.05)$, pre $2.81 \pm 0.50$ and post $2.78 \pm 0.36$ it was statistically not significant.

The self-esteem of the program was changed from pre $2.81 \pm$ 0.60 to immediately post $3.47 \pm 0.60$, showed a statistically significant $(Z=-2.37, p<0.05)$, pre-post comparison of the results showed a statistically not significant change in pre 2.81 \pm 0.60 , post $2.86 \pm 0.45(\mathrm{Z}=-0.11)$ (Table 2$)$.

\section{Verification of differences in marriage satisfaction}

Marriage satisfaction with the spinal cord injured couple increased from $4.31 \pm 2.09$ pre to $4.81 \pm 1.31$ posts, but statistically not significant. The mean score of marriage satisfaction in the spinal cord injury group was increased from $4.48 \pm 1.99$ pre to $5.24 \pm 1.50$ post, and the spouse group was also increased from $4.14 \pm 2.3$ pre to $4.38 \pm 1.01$ post, but statistically not significant in both groups (Table 3 ).

\section{Verification of differences in sexual life satisfaction}

Sexual life satisfaction with the spinal cord injured couple increased from $3.10 \pm 0.76$ pre to $3.31 \pm 0.73$ posts, but statistically not significant. The mean score of sexual life satisfaction in the spinal cord injury group was increased from $3.10 \pm 0.65$ pre to $3.15 \pm 3.16$ post, and the spouse group was also increased from $3.11 \pm 0.91$ pre to $3.48 \pm 0.78$ post, but statistically not significant in both groups (Table 4).

Table 1. Verification of differences in acceptance of disability $(N=35)$.

\begin{tabular}{|c|c|c|c|c|c|}
\hline \multirow[t]{3}{*}{ Division } & \multirow{3}{*}{$\begin{array}{l}\text { Pre } \\
\text { MD } \pm \text { SD }\end{array}$} & \multirow{3}{*}{$\begin{array}{l}\text { immediatel } \\
\text { y post } \\
M D \pm S D\end{array}$} & \multirow{3}{*}{$\begin{array}{l}\text { Post } \\
\text { MD } \pm \text { SD }\end{array}$} & \multicolumn{2}{|c|}{ Change within a group } \\
\hline & & & & $\mathbf{Z}$ & $\mathbf{Z}$ \\
\hline & & & & $\begin{array}{l}\text { Pre- } \\
\text { immediately } \\
\text { post }\end{array}$ & $\begin{array}{l}\text { Pre- } \\
\text { Post }\end{array}$ \\
\hline Couple & $2.34 \pm 0.96$ & $3.89 \pm 0.65$ & $\begin{array}{l}3.71 \\
0.78\end{array}$ & $-3.31^{\dagger}$ & $-3.19^{\dagger}$ \\
\hline $\begin{array}{l}\text { Spinal cord } \\
\text { injury }\end{array}$ & $2.46 \pm 0.51$ & $4.07 \pm 0.51$ & $\begin{array}{l}3.50 \\
0.58\end{array}$ & $-2.37^{*}$ & $-2.21^{*}$ \\
\hline Spouse & $2.21 \pm 0.81$ & $3.71 \pm 0.76$ & $\begin{array}{l}3.93 \\
0.93\end{array}$ & $-2.38^{*}$ & $-2.39^{*}$ \\
\hline
\end{tabular}

$p \leq 0.05 ; p \leq 0.001$

Table 2. Verification of differences in self-esteem $(N=35)$.

\begin{tabular}{|c|c|c|c|c|c|c|c|c|}
\hline \multirow{3}{*}{\multicolumn{2}{|c|}{ Division }} & \multirow{3}{*}{$\begin{array}{l}\text { Pre } \\
\text { MD } \\
\text { SD }\end{array}$} & \multirow{3}{*}{ \pm} & \multirow{3}{*}{$\begin{array}{l}\text { immediately } \\
\text { post } \\
M D \pm \text { SD }\end{array}$} & \multicolumn{2}{|l|}{ Post } & \multicolumn{2}{|c|}{ Change within a group } \\
\hline & & & & & \multirow{2}{*}{$\begin{array}{l}\text { MD } \\
\text { SD }\end{array}$} & \multirow[t]{2}{*}{ \pm} & $\mathbf{z}$ & $\mathbf{z}$ \\
\hline & & & & & & & $\begin{array}{l}\text { Pre-immediately } \\
\text { post }\end{array}$ & $\begin{array}{l}\text { Pre- } \\
\text { post }\end{array}$ \\
\hline Couple & & $\begin{array}{l}2.81 \\
0.53\end{array}$ & \pm & $3.45 \pm 0.49$ & $\begin{array}{l}2.81 \\
0.40\end{array}$ & \pm & $-3.19^{\dagger}$ & -0.28 \\
\hline $\begin{array}{l}\text { Spinal } \\
\text { injury }\end{array}$ & cord & $\begin{array}{l}2.81 \\
0.50\end{array}$ & \pm & $3.43 \pm 0.41$ & $\begin{array}{l}2.78 \\
0.36\end{array}$ & \pm & $-2.21^{*}$ & -0.42 \\
\hline Spouse & & $\begin{array}{l}2.81 \\
0.60\end{array}$ & \pm & $3.47 \pm 0.60$ & $\begin{array}{l}2.86 \\
0.45\end{array}$ & \pm & $-2.37^{*}$ & -0.11 \\
\hline
\end{tabular}

${ }^{*} p \leq 0.05 ; p \leq 0.001$

Table 3. Marriage satisfaction comparison $(N=35)$.

\begin{tabular}{llll}
\hline Division & Pre & Post & Change within a group \\
\cline { 2 - 3 } & MD \pm SD & MD \pm SD & $\mathrm{Z}$ \\
\cline { 3 - 3 } & & Pre-post \\
\hline
\end{tabular}




\begin{tabular}{llll}
\hline Couple & $4.31 \pm 2.09$ & $4.81 \pm 1.31$ & -1.98 \\
\hline Spinal cord injury & $4.48 \pm 1.99$ & $5.24 \pm 1.50$ & -2.03 \\
\hline Spouse & $4.14 \pm 2.34$ & $4.38 \pm 1.01$ & 0 \\
\hline
\end{tabular}

Table 4. Sexual life satisfaction comparison $(N=35)$.

\begin{tabular}{|c|c|c|c|c|}
\hline \multirow{3}{*}{\multicolumn{2}{|c|}{ Division }} & Pre & Post & Change within a group \\
\hline & & \multirow[t]{2}{*}{$M D \pm S D$} & \multirow[t]{2}{*}{$M D \pm S D$} & $\mathbf{Z}$ \\
\hline & & & & Pre-post \\
\hline Couple & & $3.10 \pm 0.76$ & $3.31 \pm 0.73$ & -1.54 \\
\hline $\begin{array}{l}\text { Spinal } \\
\text { injury }\end{array}$ & cord & $3.10 \pm 0.65$ & $3.15 \pm 3.16$ & -0.53 \\
\hline Spouse & & $3.11 \pm 0.91$ & $3.48 \pm 0.78$ & -1.47 \\
\hline
\end{tabular}

\section{Discussion}

This study is a single-group pre-post experimental design to investigate the effect of the sexual education treatment program of the spinal cord disabled on the acceptance of disability, self-esteem and marital relationship enhancement.

Disability acceptance of spinal cord injury couples was a statistically significant difference between the immediately post program and the post program. Disability acceptance of pre-immediate post and pre-post to the spinal cord injury group showed a statistically significant change. Disability acceptance of pre-immediate post and pre-post to the spinal cord injury spouse group showed a statistically significant change.

The self-esteem of the spinal cord injured couple group was statistically significant in the pre-post. The self-esteem of the spinal cord injured group was statistically significant in the pre-immediate post but it was no statistically significant change in pre-post. The self-esteem of the spinal cord injured spouse group was statistically significant in the pre-immediate post but it was no statistically significant change in pre-post.

The marital satisfaction of spinal cord injured couples was not statistically significant in the pre-post-test. The marital satisfaction of the spinal cord injury group and the spouse group was not statistically significant in pre-post.

Sexual life satisfaction of spinal cord injured couple was not statistically significant in pre-post. The total average score was increased but not statistically significant. Spinal cord injury group and spouse group were not statistically significant in pre-post.

Even in people who have the same disability, there are the feelings, attitudes, and thoughts that each individual has about his disability may appear differently, it is the concept of acceptance of disability as to how to accept the changes of the disability and its environment [9]. Most people with spinal cord disorders live well and have disabilities due to acquired causes, so it takes a lot of time to accommodate their disabilities because of past experience as a normal person. The acceptance of disability refers to adaptation through certain stages after disability, and the process reaches acceptance through denial, anger, compromise, and depression [10].

The results of the study are as follows, although spinal cord injuries suffer from difficulties in accepting disabilities, they affect socio-psychological adaptations such as self-esteem and depression, but their relationship with their spouse also affects them [11]. Although the acceptance of disability is very important for people with disabilities, the reason for the lack of research on the basis of independent standards is that disability acceptance is regarded only as a process implicit ineffective coping, adaptation, and depression research [12].

Recently spinal cord disabilities targeting 124 people 'Study on the factors affecting the spinal cord disabilities receiving disability', the acceptance of disability is a very personal psychological aspect and preceded by the influence of cognitive factors before environmental influence. In this study, the older the younger, the higher the education, the longer the time after disability, the higher the acceptance of disability. As for cognitive factors, self-concept and coping have a major influence on disability acceptance of the spinal cord. In other words, rather than being obsessed with the attribution of responsibility for the past disability, the obstacles can be accommodated when they show a positive awareness of the current physical condition and the environment changed by the disability and effective coping [13].

In another study, the demographic characteristics were better accommodated by older age and economic activity. In addition, disability acceptance was good in sports participating groups, but disability characteristics such as frequency of sports participation, cause of disability, degree of disability, and time of disability did not affect disability acceptance [14].

However, in the researcher's study, self-esteem and occupation were consistently correlated with the acceptance of disability, but not with age, education, duration of disability, the cause of disability, and degree of disability. It's showing the results of research partly contradictory Lee and Yun in the study and needs further study. [13,14].

In addition to the acceptance of disability, the part that is inevitable in the rehabilitation of the disabled is the encouragement of the spouse, and maintaining the marital status is an important factor in the happiness of the spinal cord disorders couple [15]. However, with the physical changes of the spinal cord impairment, the loss of sexual ability leads to a change in the relationship with the spouse, resulting in internal psychological change and marital conflict [16].

Therefore, in order to smooth the marriage of the couple, it was necessary to learn the skills to cooperate with a spinal cord injury or disability spouses mutual and necessary for the development of such programs [16]. In Korea, the rehabilitation program is very limited in family programs and is operated in a fragmentary manner centering on disabled welfare centers. It is difficult to maintain sustainability due to budget issues. 
The effect of sexual education program on spinal cord injured couples on disability acceptance, self-esteem, and marital relationship enhancement

It is necessary to develop a program for the better relationship of families with disabilities, in addition, the on-going operation of the family relations program is considered necessary along with the medical rehabilitation of persons with disabilities.

\section{Conclusion}

This study is a single-group pre-post experimental design to investigate the effect of the sexual education treatment program of the spinal cord disabled on the acceptance of disability, self-esteem and marital relationship enhancement.

This study by verifying the effectiveness of sexual education programs of the spinal cord disabilities to provide basic data for the program to accommodate disabilities and promote selfesteem of the spinal cord and the disabled couple, in addition, we aim to contribute to the establishment of healthy family relationships and the improvement of quality of life by promoting spousal couple's marital relationship.

\section{Conflict of Interest}

The authors report no conflicts of interest related to this study. The author does not have any financial interest in the companies whose materials are included in the article.

\section{References}

1. Korea Institute for Health and Social Affairs. Survey on the status of the disabled in 2011.

2. Kennedy P, Evans M, Sandhu N. Psychological adjustment to spinal cord injury: The contribution of coping, hope and cognitive appraisals. Psychol Health Med 2009; 14.

3. Piazza D, Holcombe J, Foote A, Paul P, Love S, Daffin P. Hope, social support and self-esteem of patients with spinal cord injuries. J Neurosci Nurs 1991; 23: 224-230.

4. Kim JJ, Yu JS, Park JW. A study on the sexual life of paraplegic patients. J Nurs 1984; 8: 1-26.

5. Park YJ, Kim JH. The effects of the dynamic group counselling on self-esteem and perceived therapeutic factors in the disabled. Korea J Counsel 2003; 4: 223-235.

6. Lee ES, Sin EK. A study on the disability identity scale (DIS)-for persons with spinal cord injury. Korea Disabl Welfare Assoc 2006; 5: 111-141.
7. Rubinstein G. The big five and self-esteem among overweight dieting and non-dieting women. Eat Behav 2006; 7: 355-361.

8. Jeong SM. Effect of sexual education program for patients with lumbar disc surgery. Yonsei University Graduate School of Health Masters Thesis 2003; 1-79.

9. Dembo T, Leviton G, Wright BA. Adjustment to misfortune; a problem of social-psychological rehabilitation. Rehab Psychol 1956; 22: 1-100.

10. Bracken MB, Shepard MJ, Webb SB. Psychological response to acute spinal cord injury: an epidemiological study. Paraplegia 1981; 19: 271-283.

11. Kang HS, Suh YO. A comparison of the sexual concerns of men and women with spinal cord injuries. Korean Acad Soc Rehab Nurs 2001; 4: 198-206.

12. Jo AR. The effects of self-focusing attention on disability admission and depression. Yonsei University Graduate School of Health Masters Thesis 1997; 1-50.

13. Yun SY. A study on factors that influence on acceptance of disability of the spinal cord injury. Gyeongsang National University Masters Thesis 2003; 1-63.

14. Lee WC. The impact of sports participation on the disability reception of the disabled with spinal cord injuries. Catholic University of Daegu Masters Thesis 2007; 1-54.

15. DeVivo MJ, Fine PR. Spinal cord injury: its short-term impact on marital status. Arch Phys Med Rehabil 1985; 66: 501-504.

16. Yoo YS. (The) Problems of couples with spinal cord injury and the application of the couple-relationimprovement-program. Family Fam Ther 1999; 7: 45-73.

\section{*Correspondence to}

Young-Soon Choi

Department of Nursing

College of Health Science

Kangwon National University

Republic of Korea 